Proc. Indian Acad. Sci. (Chem. Sci.), Vol. 106, No. 2, April 1994, pp. 579-589.

(C) Printed in India.

\title{
Effect of the valine-threonine constraint on the dynamics of the proline helix - A molecular dynamics study
}

\author{
S SHOBANA, GAUTHAM NADIG and \\ SARASWATHI VISHVESHWARA* \\ Molecular Biophysics Unit, Indian Institute of Science, Bangalore 560012, India
}

\begin{abstract}
Proline residues in helices play an important role in the structure of proteins. The proline residue introduces a kink in the helix which varies from about $5^{\circ}$ to $50^{\circ}$. The presence of other residues such as threonine or valine near the proline region can influence the flexibility exhibited by the kinked helix, which can have an important biological role. In the present paper, the constraint introduced by threonine and valine on a proline helix is investigated by molecular dynamics studies. The systems considered are (1) a poly-alanine helix with threonine-proline residues (TP) and (2) a poly-alanine helix with valine-threonineproline residues (VTP), in the middle. Molecular dynamics simulations are carried out on these two systems for 500 ps. The results are analyzed in terms of structural transitions, bend-related parameters and sidechain orientations.
\end{abstract}

Keywords. Proline helix; valine-threonine constraint; molecular dynamics.

\section{Introduction}

It has been well-recognized that proline residues in proteins have important structural and functional roles to play. Their structural roles in turns, bends and helices are well established (Chou and Fasman 1974, 1977; Anfinsen and Scheraga 1975; Robson and Suzuki 1976; Rose et al 1985; Brandl and Deber 1986; Barlow and Thornton 1988; Richardson and Richardson 1988; Woolfson and Williams 1990; MacArthur and Thornton 1991). We have been particularly interested in characterizing the bend introduced by proline in helices and examining the effect of constraints on such helices (Sankararamakrishnan and Vishveshwara 1990-1993). Recently, we had focused on the constraints introduced by threonine in different positions on a proline helix which gave rise to a variety of bent structures during molecular dynamics simulation (Shobana and Vishveshwara 1993). It appears that the nature of the bend introduced by proline in helices and the extent of flexibility exhibited by the secondary structure can be modulated by certain types of constraints.

Recent studies have shown that repetitive sequences containing alanine-threonineproline (ATP) and valine-threonine-proline (VTP) appear in nucleolin, a ubiquitous protein in eukaryotic cells, which is thought to play a direct role in pre-RNA transcription and ribosome assembly (Lapeyre et al 1987; Suzuki 1991). Hence we believe it is interesting to study the structure and dynamics of the helices which contain ATP and VTP sequences. The present work is intended to gain an

\footnotetext{
*For correspondence
} 
understanding of the constraint introduced by a bulky residue (valine) on the proline helix.

The dynamics of a helix with ATP sequence was previously investigated for $200 \mathrm{ps}$ (Shobana and Vishveshwara 1993), in which a highly bent structure (DP2) was found until $140 \mathrm{ps}$ and a normal helix (DP1) with proline was observed between $140 \mathrm{ps}$ and $200 \mathrm{ps}$. In the present study, the simulation on ATP is extended up to 500 ps in order to see if further structural transitions occur. The VTP system is simulated for $500 \mathrm{ps}$ under identical conditions. The results of the two simulations are compared and the extent of rigidity introduced by valine on the structural transitions, fluctuations in the bend in the helical structure, and the sidechain orientation of the threonine residue, are discussed.

\section{Methods}

To explore the conformational properties of proline containing $\alpha$-helices with constraints, two systems were chosen. They are (1) ATP: Ace-(Ala) $)_{12}-$ Thr-Pro-(Ala) $)_{10}-\mathrm{NHMe,}$ and (2) VTP: Ace-(Ala) ${ }_{11}-$ Val-Thr-Pro- $(\text { Ala })_{10}-$ NHMe. The system 2 has a valine in addition to threonine as the constraint. The valine orientation was chosen such that the $\mathrm{N}-\mathrm{C}^{\alpha}-\mathrm{C}^{\beta}-\mathrm{H}^{\gamma}$ is $+60^{\circ}$ (Bhat et al 1979; Benedetti 1977). In the two systems, the initial conformation includes the hydrogen bond interaction between the $\mathrm{O}^{\gamma}$ of threonine sidechain and the carbonyl oxygen of the $p-5$ th residue. The $200 \mathrm{ps}$ simulation of ATP has been already reported (Shobana and Vishveshwara 1993). The nomenclature used for the ATP system and the two structures obtained during the simulation are DP, DP1 and DP2 in the earlier study (Shobana and Vishveshwara 1993) and TP, TP1 and TP2 in the present study respectively. The structure for VTP is generated from the starting unoptimized structure of TP by replacing the alanine below threonine by valine and is designated as VTP.

The initial structures were energy minimized using the AMBER program (Weiner and Kollman 1981; Weiner et al 1984, 1986) adapted to run on an INTEL 860 machine in which the potential function describing the interaction of the system has the following form

$$
\begin{aligned}
E_{\text {total }}= & \sum_{\text {bonds }} K_{R}\left(R-R_{0}\right)^{2}+\sum_{\text {angles }} K_{\theta}\left(\theta-\theta_{0}\right)^{2} \\
& +\sum_{\text {dihedrals }} V_{n} / 2[1+\cos (n \phi-\gamma)] \\
& +\sum_{i<j \text { non-bonded }}\left[B_{i j} /\left(R_{i j}\right)^{12}-A_{i j} /\left(R_{i j}\right)^{6}+q_{i} q_{j} / \varepsilon R_{i j}\right] \\
& +\sum_{\text {H-bonds }}\left[C_{i j} /\left(R_{i j}\right)^{12}-D_{i j} /\left(R_{i j}\right)^{10}\right] .
\end{aligned}
$$

The partial atomic charges and the force field parameters used were those provided in AMBER. All atoms including the hydrogens were considered in the calculations. A distance-dependent dielectric constant $\varepsilon r_{i j}=r_{i j}$ was employed for the evaluation of electrostatic interaction energies. The structures were refined until the r.m.s. gradient of energy was less than $0.001 \mathrm{kcal} / \mathrm{mol} \AA$. For the minimization of the two systems, 
a steepest descent method was used for the first 1000 cycles and then a conjugate gradient method was used until convergence.

MD studies were carried out on TP and VTP using the AMBER-MD module. All bonds involving hydrogens were constrained using the SHAKE algorithm. Simulations were carried out in vacuum at $300 \mathrm{~K}$. During the heating process the temperature was raised drastically and the system reached the temperature of $300 \mathrm{~K}$ in about $0.3 \mathrm{ps}$. A time step of $0.001 \mathrm{ps}$ was chosen and the MD run was performed for $500 \mathrm{ps}$ including an equilibration period of $25 \mathrm{ps}$. The atomic coordinates were stored at $0.1 \mathrm{ps}$ interval. A few points from the MD trajectories of TP and VTP were minimized to a convergence of $0.005 \mathrm{kcal} / \mathrm{mol} \AA$.

The two simulations were then analyzed in terms of their conformational parameters; backbone dihedral angles $\phi, \psi$ and $\omega$, and the virtual torsion angles as described in figure 1 . The bend due to proline was characterized by means of kink angle $(\theta)$ (Sankararamakrishnan and Vishveshwara 1991), and the virtual torsion angle $C_{p-3}^{\alpha}-C_{p-2}^{\alpha}-C_{p-1}^{\alpha}-C_{p}^{\alpha}\left(V_{p}\right)$. In addition, to monitor the alpha helical nature, hydrogen bond interactions were analyzed as described in the earlier report (Shobana and Vishveshwara 1993). The backbone hydrogen bond $\mathrm{N}_{p+1} \cdots \mathrm{O}_{p-3}$ is designated as $h_{\rho}$. The sidechain-backbone hydrogen bonds of threonine $\mathrm{O}^{\gamma+1} \cdots \mathrm{O}_{p-4}$ and $\mathrm{O}^{\gamma} \cdots \mathrm{O}_{p-5}$ are designated as $d_{i-i-3}$ and $d_{i-i-4}$, respectively. The proline pucker was monitored by means of the ring dihedrals $\chi_{1}\left(N-C^{\alpha}-C^{\beta}-C^{\gamma}\right)$ and $\chi_{2}\left(C^{\alpha}-C^{\beta}-C^{\gamma}-C^{\delta}\right)$. When $\chi_{1}$ has positive values and $\chi_{2}$ has negative values, the proline is said to have DOWN pucker and when $\chi_{1}$ is negative and $\chi_{2}$ is positive it is said to have UP pucker (Sankararamakrishnan and Vishveshwara 1991). The valine sidechain was monitored by means of dihedral angle $\chi_{1}\left(\mathrm{~N}-\mathrm{C}^{\alpha}-\mathrm{C}^{\beta}-\mathrm{H}^{\beta}\right)$.

\section{Results and discussion}

MD studies have been carried out on proline containing $\alpha$-helices with constraints in the form of threonine and threonine with valine. The results and analysis of the MD simulation of TP and VTP systems are presented here.

The trajectories of helix bend parameters $\left(\theta\right.$ and $\left.V_{\rho}\right)$ and threonine-related structural parameters $\left(\chi_{i}, d_{i-i-3}\right.$ and $\left.d_{i-i-4}\right)$ of the TP system are given in figure $2 \mathrm{a}$. Similar trajectories for VTP system are given in figure 3 . The TP system assumes a highly bent conformation between 25 and 140 ps. The potential energy of the system given in figure $2 b$ (including the equilibration period) do not exhibit any conspicuous changes which indicates that the system is stable at $300 \mathrm{~K}$ and sufficiently equilibrated. The characteristics of the structure (TP2) between 25 and 145 ps was discussed earlier (Shobana and Vishveshwara 1993) and is a bent structure in which an $i \rightarrow i-2$ hydrogen bond $\left(\mathrm{N}_{p-1} \cdots \mathrm{O}_{p-3}\right)$ has gained stability and $\psi_{p-2}$ has assumed a value around $+45^{\circ}$. The features observed are characteristic of bends and are clear indications of a non-helical nature. The kink angle $(\theta)$, the virtual torsion angle $\left(V_{p}\right)$ and the threonine sidechain $\left(\chi_{t}\right)$ assume values around $76^{\circ}, 156^{\circ}$ and $-17^{\circ}$, respectively, which can be seen from figure $2 \mathrm{a}$. The threonine $\mathrm{O}^{\gamma}$ has a good $d_{i-i-3}$ hydrogen bond $\left(d_{i-i-3}\right)$ with the carbonyl backbone $O$ of the $i-3$ residue in this conformation. After $140 \mathrm{ps}$, the system returns to a normal proline helix structure $\left(V_{\rho} \sim 71^{\circ}, \theta \sim 39^{\circ}\right)$ and remains in this conformation until $500 \mathrm{ps}$. During this period the threonine $\chi$ value is maintained around $-60^{\circ}$ with a brief transition to $+60^{\circ}$ 

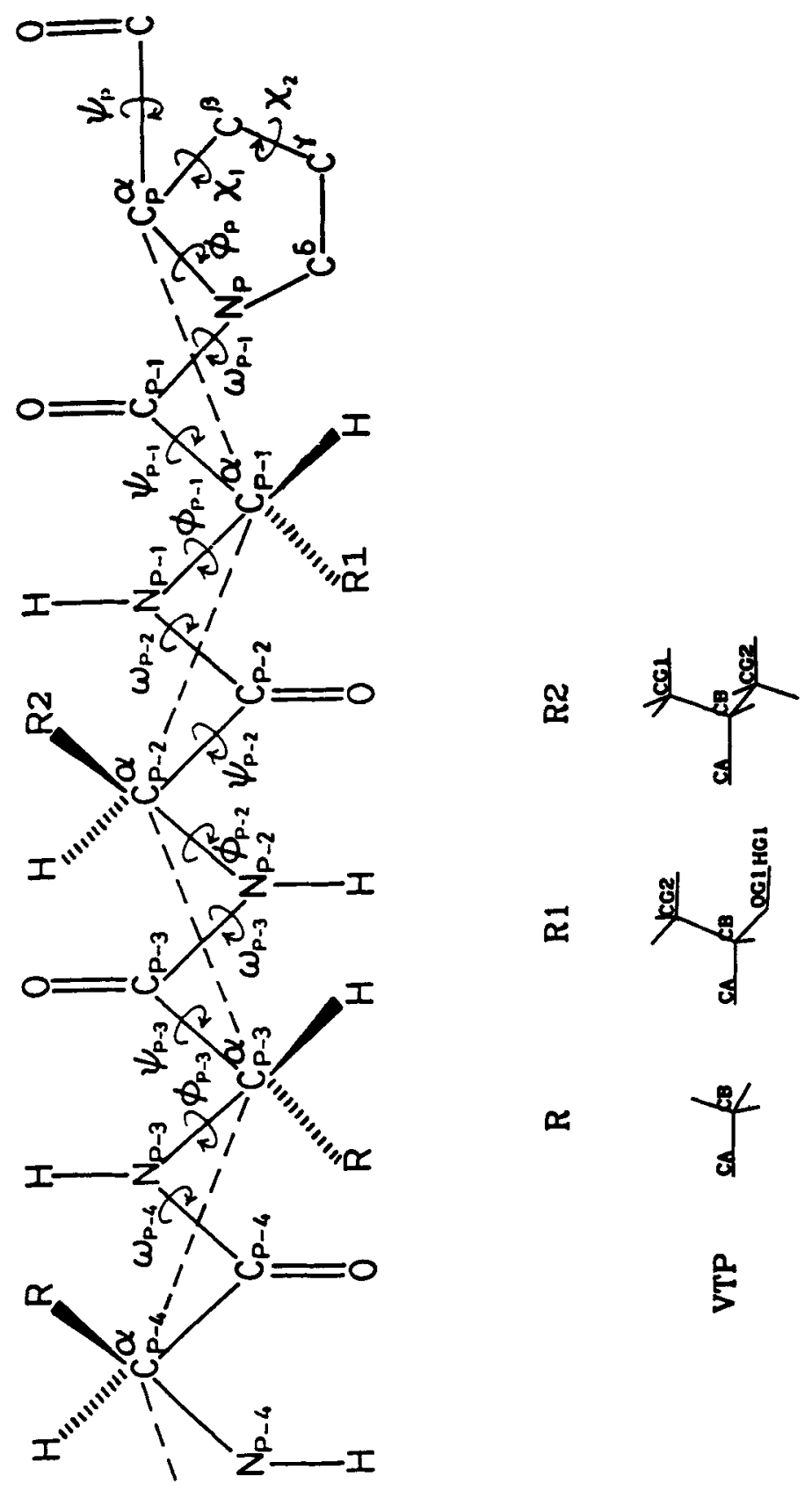<smiles>C=C[Ge](C)(C)C(O)=S</smiles>

또<smiles>CC(C)(C)C</smiles>

5

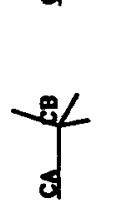

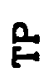



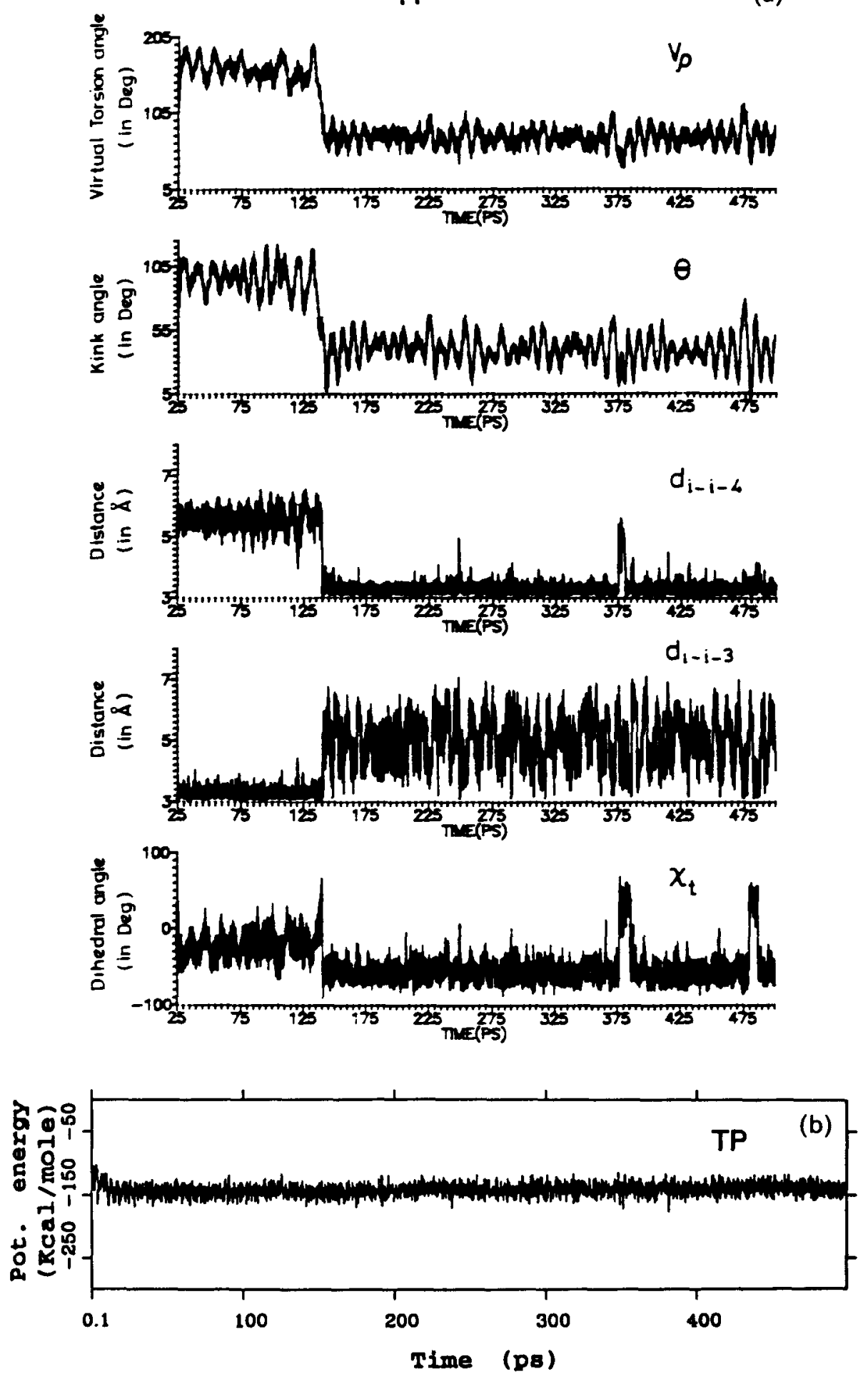

Figure 2. The MD trajectories of (a) dihedral angles: $V_{p}, \theta$ and $\chi_{s}$, and hydrogen bond distances: $d_{i-i-4}$ and $d_{i-i-3}$, (b) potential energy (including the equilibration period) of the simulation with TP as the initial conformation. 

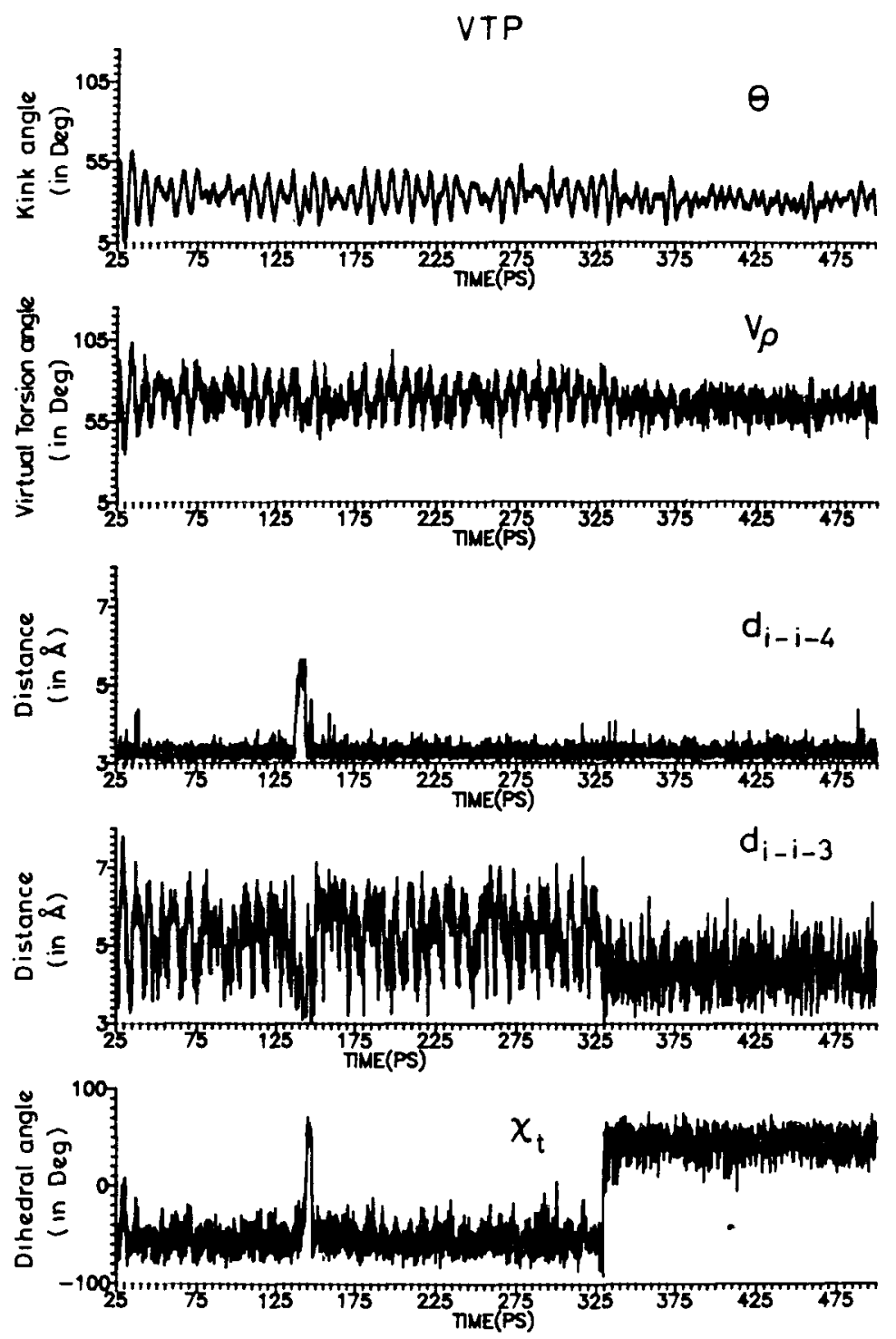

Figure 3. The MD trajectories of dihedral angles: $V_{\rho}, \theta$ and $\chi_{t}$ and hydrogen bond distances: $d_{i-i-4}$ and $d_{i-i-3}$ of the simulation with VTP as the initial conformation.

around 140,380 and $480 \mathrm{ps}$. In this conformation $d_{i-i-4}$ is stable whereas the distance between $\mathrm{O}^{y}$ of threonine and the $i-3 \mathrm{rd}$ carbonyl oxygen varies between $3 \cdot 28 \AA$ and $5 \cdot 31 \AA$. However, these transitions have no major significance from the overall structure point of view since the analysis of the backbone parameters did not exhibit any marked fluctuations. The kink and virtual torsion angles exhibit an interesting periodicity of large fluctuations about the mean value dampening to small fluctuations. The fluctuations lead to structures ranging from an almost straight helix $\left(\theta \sim 7^{\circ}\right)$ to a kink of about $75^{\circ}$. A stereo plot of the two minimized structures with extreme kink angles are given in figure 4. 

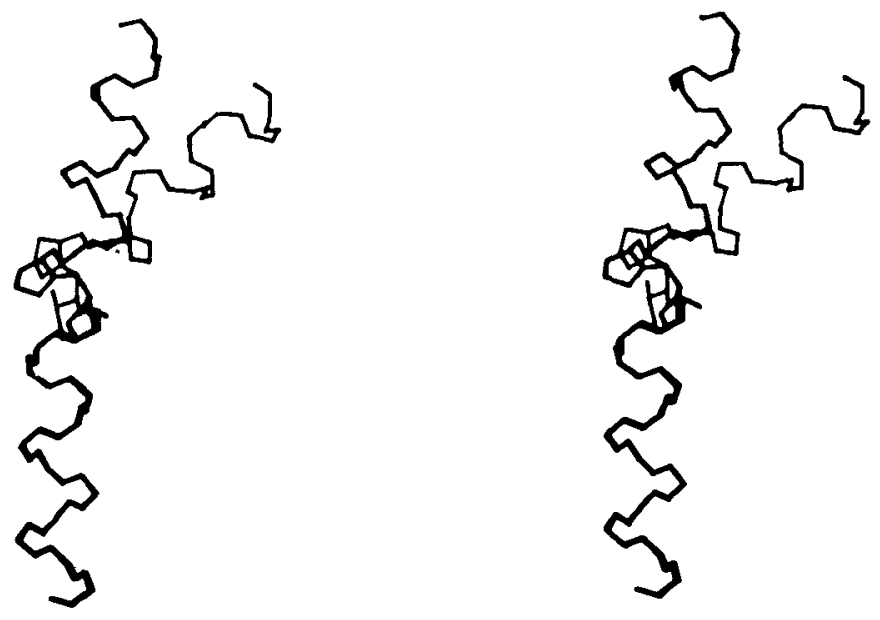

Figure 4. A stereo plot of the backbone atoms along with proline and threonine sidechain atoms of the superposed minimized structures taken from TP simulation at $475.2 \mathrm{ps}$ (high kink angle) and $480 \cdot 1$ ps (low kink angle).

A comparison of TP and VTP systems shows that the highly bent TP2 structure (25-140 ps) is not accessed by the VTP system (figure 3). The VTP system remains in the normal proline helix form throughout the $500 \mathrm{ps}$ simulation in which the $d_{i-i-4}$ is stable. The virtual torsion and kink angles fluctuate around $69^{\circ}$ and $34^{\circ}$ respectively. The valine sidechain has remained at the initial conformation of $\chi_{1} \sim+60^{\circ}$ throughout. The threonine sidechain $\left(\chi_{t}\right)$ has however changed from $-60^{\circ}$ to $+60^{\circ}$ around $320 \mathrm{ps}$ and has remained at $+60^{\circ}$ until $500 \mathrm{ps}$.

A correlation is exhibited between the bending behavior of the helix (fluctuations in $V_{\rho}$ and $\theta$ ) and $\chi_{t}$. When $\chi_{t}$ is $60^{\circ}$, the fluctuations in the bend-related parameters are lesser than when $\chi_{t}$ is $-60^{\circ}$. Hence the system has assumed two structures VTP1 $(25-320 \mathrm{ps})$ and VTP2 $(320-500 \mathrm{ps})$ of very similar bend with subtle differences in their flexibility.

TP1 structure of TP, VTP1 and VTP2 structures of VTP have a bend similar to that of a normal proline helix while few differences are seen in their flexibility. The $\phi, \psi, \omega$ parameters of significance, $\chi_{t}$ and bend-related parameters of the three structures are listed in tables 1 and 2, respectively. The backbone parameters listed in table 1 show that all the three structures exhibit the characteristics of a normal proline helix. For instance, the average values of dihedral angles $\left(\phi_{p-3}, \psi_{p-3}\right),\left(\phi_{p-2}\right.$, $\left.\psi_{p-2}\right)$ correspond to the $\alpha_{11}$ helix and that of $\left(\phi_{p-1}, \psi_{p-1}\right)$ correspond to the goniometric helix values (Sankararamakrishnan and Vishveshwara 1993). There is a small difference in the flexibility of the backbone dihedral angles as can be seen in the r.m.s. deviations (table 1). However, significant differences can be seen in the threonine $\chi_{t}$ values which correlate with those of the bend-related parameters $\left(\theta, V_{\rho}\right.$ and $h_{\rho}$ ) as shown in figures $2 \mathrm{a}$ and 3 and table 2 . Thus, the orientation of the threonine sidechain which is influenced by preceding valine residue has considerable influence on the flexibility of the bend due to proline in the helix.

The proline pucker is another interesting parameter for analysis (Sankararamakrishnan and Vishveshwara 1992). The trajectories of $\chi_{1}$ and $\chi_{2}$ of proline for TP and VTP 
Table 1. The backbone dihedral angles (in degrees) for the two simulationsTP and VTP are given. The three, entries for every parameter listed are the MD average, the r.m.s. deviation (in parentheses) and the MD minimized structure (in square brackets).

\begin{tabular}{|c|c|c|c|}
\hline $\begin{array}{l}\text { Dihedral } \\
\text { angles }\end{array}$ & TP1 & VTP1 & VTP2 \\
\hline$\phi_{p-4}$ & $\begin{array}{c}-57.580 \\
( \pm 9.572) \\
{[-54.887-61.737]^{*}}\end{array}$ & $\begin{array}{c}-57.978 \\
( \pm 9.874) \\
{[-57.943]}\end{array}$ & $\begin{array}{r}-58 \cdot 770 \\
( \pm 9 \cdot 400) \\
{[-55.646]}\end{array}$ \\
\hline$\psi_{p-4}$ & $\begin{array}{c}-44.046 \\
( \pm 11 \cdot 649) \\
{[-51 \cdot 361-30 \cdot 255]}\end{array}$ & $\begin{array}{c}-40.852 \\
( \pm 12.941) \\
{[-41.443]}\end{array}$ & $\begin{array}{l}-36.411 \\
( \pm 11.591) \\
{[-42.835]}\end{array}$ \\
\hline$\phi_{p-3}$ & $\begin{array}{c}-66 \cdot 889 \\
( \pm 12 \cdot 433) \\
{[-57.964-77 \cdot 103]}\end{array}$ & $\begin{array}{l}-69.788 \\
( \pm 13.638) \\
{[-67.985]}\end{array}$ & $\begin{array}{c}-73 \cdot 241 \\
( \pm 12 \cdot 109) \\
{[-67 \cdot 736]}\end{array}$ \\
\hline$\psi_{p-3}$ & $\begin{array}{c}-43.763 \\
( \pm 10.040) \\
{[-45.033-52 \cdot 992]}\end{array}$ & $\begin{array}{c}-45.680 \\
( \pm 10.792) \\
{[-51.236]}\end{array}$ & $\begin{array}{c}-47.397 \\
( \pm 9.512) \\
{[-49.872]}\end{array}$ \\
\hline$\phi_{p-2}$ & $\begin{array}{c}-66.696 \\
( \pm 11 \cdot 370) \\
{[-64.159-54.980]}\end{array}$ & $\begin{array}{c}-66.394 \\
( \pm 11.603) \\
{[-70.760]}\end{array}$ & $\begin{array}{c}-67.865 \\
( \pm 11 \cdot 223) \\
{[-66.330]}\end{array}$ \\
\hline$\psi_{p-2}$ & $\begin{array}{c}-44.451 \\
( \pm 12.324) \\
{[-43.648-46.633]}\end{array}$ & $\begin{array}{l}-46.292 \\
( \pm 11 \cdot 141) \\
{[-51 \cdot 710]}\end{array}$ & $\begin{array}{r}-50.173 \\
( \pm 9.634) \\
{[-52.747]}\end{array}$ \\
\hline$\omega_{p-2}$ & $\begin{array}{c}-171 \cdot 325 \\
( \pm 8 \cdot 133) \\
{[-172 \cdot 239-175 \cdot 258]}\end{array}$ & $\begin{array}{r}-171.486 \\
( \pm 7.991) \\
{[165.157]}\end{array}$ & $\begin{array}{r}-170-269 \\
( \pm 7.871) \\
{[-171 \cdot 271]}\end{array}$ \\
\hline$\phi_{p-1}$ & $\begin{array}{c}-47.534 \\
( \pm 12.786) \\
{[-27.206-60.896]}\end{array}$ & $\begin{array}{l}-47.460 \\
( \pm 11.508) \\
{[-55.252]}\end{array}$ & $\begin{array}{l}-51 \cdot 196 \\
( \pm 10 \cdot 292) \\
{[-42 \cdot 642]}\end{array}$ \\
\hline$\psi_{p-1}$ & $\begin{array}{c}-57.642 \\
( \pm 9.098) \\
{[-63.892-63.892]}\end{array}$ & $\begin{array}{r}{[-57.748} \\
( \pm 8.749) \\
{[-48.846]}\end{array}$ & $\begin{array}{r}-54.560 \\
( \pm 9.133) \\
{[-56.919]}\end{array}$ \\
\hline$\phi_{\nu}$ & $\begin{array}{c}-56.055 \\
( \pm 9.966) \\
{[-57.641-42.377]}\end{array}$ & $\begin{array}{c}-57.589 \\
( \pm 9.594) \\
{[-56.111]}\end{array}$ & $\begin{array}{r}-57.986 \\
( \pm 9.918) \\
{[-61.037]}\end{array}$ \\
\hline$\psi_{p}$ & $\begin{array}{c}-45.900 \\
( \pm 9.955) \\
{[-46.811-52 \cdot 126]}\end{array}$ & $\begin{array}{c}-44.347 \\
( \pm 9.767) \\
{[-48.103]}\end{array}$ & $\begin{array}{c}-44.783 \\
( \pm 9.883) \\
{[-43.962]}\end{array}$ \\
\hline$\phi_{p+1}$ & $\begin{array}{c}-61.084 \\
( \pm 9.823) \\
{[-65.050-56 \cdot 265]}\end{array}$ & $\begin{array}{r}-60.906 \\
( \pm 9.765) \\
{[-60.960]}\end{array}$ & $\begin{array}{r}-60.322 \\
( \pm 9.824) \\
{[-61 \cdot 112]}\end{array}$ \\
\hline$\psi_{p+1}$ & $\begin{array}{c}-47.786 \\
( \pm 8 \cdot 455) \\
{[-45 \cdot 259-51 \cdot 229]}\end{array}$ & $\begin{array}{r}-47.996 \\
( \pm 8.577) \\
{[-48.929]}\end{array}$ & $\begin{array}{r}-48.569 \\
( \pm 8.452) \\
{[-47.897]}\end{array}$ \\
\hline
\end{tabular}

* The two entries correspond to the two minimized structures: (a) a high kink structure at $475 \cdot 2 \mathrm{ps}$ and (b) a low kink structure at $480 \cdot 1 \mathrm{ps}$. 
Table 2. The constraint parameters and the bend related parameters in the two simulations - TP and VTP are given. The three entries for every parameter listed are the MD average, the r.m.s. deviation (in parentheses) and the MD minimized structure (in square brackets). The distances given are in $\AA$ and the angles are in degrees.

\begin{tabular}{|c|c|c|c|}
\hline & TP1 & VTP1 & VTP2 \\
\hline \multicolumn{4}{|c|}{ Constraint parameters } \\
\hline $\begin{array}{l}O^{y} \cdots O_{p-5} \\
\left(d_{t-i-k}\right)\end{array}$ & $\begin{array}{c}2.827 \\
( \pm 0.245) \\
{[2.7522 .736]^{*}}\end{array}$ & $\begin{array}{r}2.829 \\
( \pm 0.312) \\
{[2.748]}\end{array}$ & $\begin{array}{r}2.786 \\
( \pm 0.127) \\
{[2.761]}\end{array}$ \\
\hline $\begin{array}{l}O^{\gamma} \cdots O_{p-4} \\
\left(d_{t-1-3}\right)^{-4}\end{array}$ & $\begin{array}{c}4.495 \\
( \pm 0-815) \\
{[3.4654 .096]}\end{array}$ & $\begin{array}{r}4.767 \\
( \pm 0.828) \\
{[5.501]}\end{array}$ & $\begin{array}{r}3.896 \\
( \pm 0.537) \\
{[3.433]}\end{array}$ \\
\hline $\begin{array}{l}\mathrm{N}-\mathrm{C}^{\mathrm{a}}-\mathrm{C}^{\prime}-\mathrm{O}^{\prime} \\
\left(x_{\ell}\right)\end{array}$ & $\begin{array}{c}-51.034 \\
( \pm 22.243) \\
{[-63.51937 .046]}\end{array}$ & $\begin{array}{c}-52 \cdot 488 \\
( \pm 17 \cdot 300) \\
{[-48 \cdot 312]}\end{array}$ & $\begin{array}{r}44 \cdot 140 \\
( \pm 11 \cdot 721) \\
{[+44.873]}\end{array}$ \\
\hline $\begin{array}{l}\mathrm{N}-\mathrm{C}^{a}-\mathrm{C}^{\prime}-\mathrm{H}^{\prime} \\
\left(x_{1}\right)\end{array}$ & & $\begin{array}{c}+57.415 \\
{[ \pm 7 \cdot 216]} \\
{[+52.493]}\end{array}$ & $\begin{array}{c}+57.013 \\
{[ \pm 7.011]} \\
{[+53.465]}\end{array}$ \\
\hline \multicolumn{4}{|c|}{ Bend-related parameters } \\
\hline $\begin{array}{l}\mathbf{N}_{p+1} \cdots O_{p-3} \\
\text { (hp) }\end{array}$ & $\begin{array}{c}4 \cdot 188 \\
( \pm 0-603) \\
{[4.8212 \cdot 905]}\end{array}$ & $\begin{array}{r}4094 \\
( \pm 0-546) \\
{[4-046]}\end{array}$ & $\begin{array}{r}3.939 \\
( \pm 0-436) \\
{[4-002]}\end{array}$ \\
\hline$V_{p}$ & $\begin{array}{c}71.557 \\
( \pm 11.749) \\
{[89.92652 .810]}\end{array}$ & $\begin{array}{r}69.521 \\
( \pm 9.713) \\
{[62.643]}\end{array}$ & $\begin{array}{r}64.263 \\
( \pm 6.416) \\
{[68.384]}\end{array}$ \\
\hline $\begin{array}{l}\text { Kink angle } \\
(\theta)\end{array}$ & $\begin{array}{c}39.452 \\
( \pm 11 \cdot 184) \\
{[55.82320 .617]}\end{array}$ & $\begin{array}{r}34.060 \\
( \pm 8.559) \\
{[29.716]}\end{array}$ & $\begin{array}{r}30.691 \\
( \pm 5.293) \\
{[35.668]}\end{array}$ \\
\hline
\end{tabular}

* The two entries correspond to the two minimized structures: (a) a high kink structure at $475 \cdot 2 \mathrm{ps}$ and (b) a low kink structure at $480-1 \mathrm{ps}$.

simulations are given in figure 5. Both UP and DOWN conformations are accessed throughout the simulation, a result which is consistent with the crystal structure analysis (Milner-White et al 1992). Further in the TP system the UP conformation is predominantly seen for the TP2 structure. In the VTP system, valine seems to have played a role in keeping the proline in the DOWN conformation for most of the time.

\section{Conclusions}

A comparison of the characteristics derived from the two simulations

$$
\begin{aligned}
& \text { Ace-(Ala) } \left.)_{12}-\text { Thr-Pro-(Ala) }\right)_{10}-\text { NHMe (TP) and } \\
& \text { Ace-(Ala) } \left.)_{11}-\text { Val-Thr-Pro-(Ala) }\right)_{10}-\text { NHMe (VTP) }
\end{aligned}
$$

have shown that the bulky hydrophobic group valine restricts major structural transitions in the proline helix. 
VTP

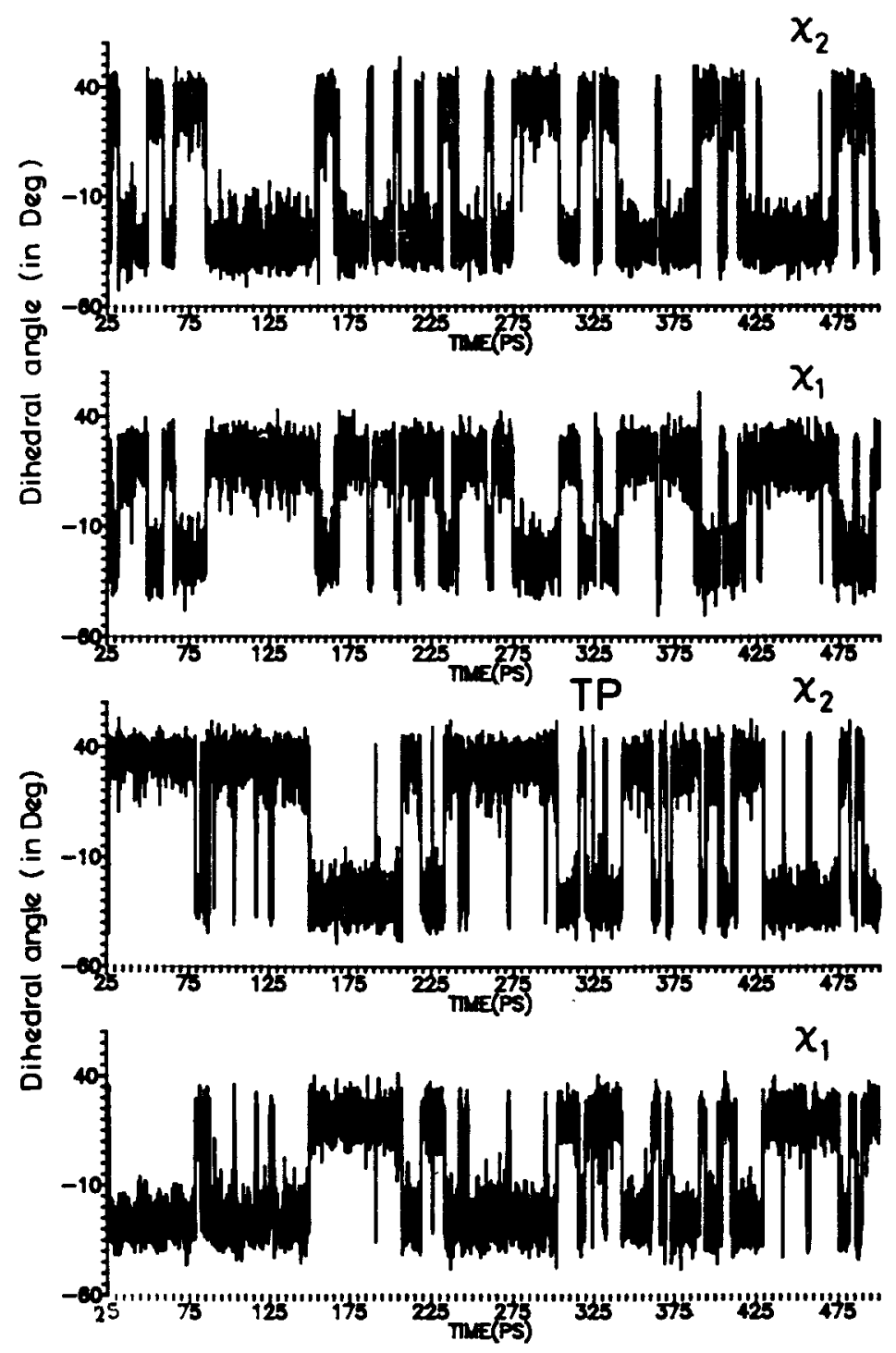

Figure 5. The MD trajectories of the proline sidechain dihedral of the simulation with TP and VTP as the initial conformation.

The normal proline helix conformation has a flexible bend wherein the structure fluctuates with kink angle varying from $5^{\circ}$ to about $55^{\circ}$, such periodic behaviour is seen throughout the VTP simulation and from $150-500$ ps of the TP simulation.

Both $g^{+}$and $g^{-}$orientations are taken up by the threonine residue. In VTP system, when $\mathrm{N}-\mathrm{C}^{\alpha}-\mathrm{C}^{\beta}-\mathrm{O}^{\gamma}\left(\chi_{t}\right)$ is $\mathrm{g}^{+}\left(\sim 60^{\circ}\right)$, the average bend and the fluctuations in bend related parameters (kink angle $(\theta)$, virtual torsion angle $\left(V_{\rho}\right)$ and the hydrogen bond $\mathrm{N}_{p+1} \cdots \mathrm{O}_{p-3}\left(h_{\rho}\right)$ are relatively less.

The proline ring accesses both the UP and DOWN pucker consistent with crystal 
structure analysis. In TP2 structure, the proline ring spends most of the time in UP pucker. In VTP system the valine residue has played a role in keeping the proline ring in the DOWN conformation for most of the simulation period.

Thus, the introduction of residues like threonine and valine in a proline containing $\alpha$-helix modulates the dynamics and the bend characteristics of the proline helix and the conformation adopted by proline.

\section{Acknowledgements}

This work was partially supported by the Council of Scientific and Industrial Research Scheme No. 09/0326/91-EMR-II. We wish to thank the DBT-supported Distributed Information Centre, Bioinformatics and the Interactive Graphics Facility at the Indian Institute of Science, Bangalore for computing facilities. One of us (GN) would like to thank Council of Scientific and Industrial Research for a fellowship.

\section{References}

Anfinsen C B and Scheraga H A 1975 Adv. Protein Chem. 29205

Barlow D J and Thornton J M $1988 \mathrm{~J}$. Mol. Biol. 201601

Benedetti E 1977 Peptides-Proc. Am. Peptide Symp. (ed.) M Goodman \& J Meienhofer (New York: John Wiley \& Sons)

Bhat T N, Sasisekharan V and Vijayan M 1979 Int. J. Peptide Protein Res. 13170

Brandl C J and Deber C M 1986 Proc. Natl. Acad. Sci. USA 83917

Chou P Y and Fasman G D 1974 Biochemistry 13211

Chou P Y and Fasman G D 1977 J. Mol. Biol. 115135

Lapeyre B, Bourbon H and Amalric F 1987 Proc. Natl. Acad. Sci. ÚSA 841472

MacArthur M W and Thornton J M 1991 J. Mol. Biol. 218397

Milner-White E J, Bell L H and Maccallum P H 1992 J. Mol. Biol. 228725

Richardson J S and Richardson D C 1988 Science 2401648

Robson B and Suzuki E 1976 J. Mol. Biol. 107327

Rose G D, Gierasch L M and Smith J A 1985 Adv. Protein Chem. 371

Sankararamakrishnan R and Vishveshwara S 1990 Biopolymers 30287

Sankararamakrishnan R and Vishveshwara S 1991 Biophys. Chem. 4097

Sankararamakrishnan R and Vishveshwara S 1992 Int. J. Peptide Protein Res. 39356

Sankararamakrishnan R and Vishveshwara S 1993 Proteins - Struct. Function Genet. 1526

Shobana S and Vishveshwara S 1993 Biophys. Chem. 4677

Suzuki M 1991 Nucleic Acids Mol. Biol. (eds) F Eckstein and D M J Lilley (Berlin, Heidelberg: Springer-Verlag) 5126

Weiner P and Kollman P A 1981 J. Comput. Chem. 2287

Weiner S J, Kollman P A, Case D A, Singh U C, Ghio C, Alagona G, Profeta Jr S and Weiner P 1984 J. Am. Chem. Soc. 106765

Weiner S J, Kollman P A, Nguyen D J and Case D A 1986a J. Comput. Chem. 7230

Weiner P K, Singh U C, Kollman P A, Caldwell J and Case D A 1986b A molecular mechanics and dynamics program - AMBER, (University of California, San Francisco)

Woolfson D N and Williams D H 1990 FEBS Lett. 277185 